\title{
Practice and Exploration of Micro-Learning Resource Based on Mobile Network
}

\author{
Wenliang Liu \\ Hechi University, Yizhou City, Guangxi, China \\ liuwenliang@hotmail.com
}

Keywords: Micro-learning; Micro-lecture; Micro-class; Mobile network

\begin{abstract}
Micro-learning resource is a new product of mobile Internet with the characteristics of visualization, fragmentation, structuring and nonlinearity in the era of the Internet. Analyzing the design and the construction principles of the micro-course, the paper presents a brief and acceptant concept and discusses the feasibility and the method of using mobile Internet platform to design and cultivate micro-course, exploring the new mode of development and application of micro-course.
\end{abstract}

\section{Introduction}

As the appearance of such E-commerce as Taobao mall has changed the pattern of consumption of the Chinese people, the new information technology as representatives of information technology, mobile Internet, cloud computing, big data, Internet, wireless technology, streaming media technology will also change the development mode of the information service in higher education, playing an important role in exploring the higher education. Nowadays, college students are growing up with internet [1]. Smartphone has a very broad application prospect in education [2]. Mobile communication tools, such as smart phones, as the main entrance in the era of the mobile Internet, has been fully integrated into the information life of the public and will provide a good new way of ascension for improving the higher service and higher education. Higher education has a new vitality in the growing popularity of mobile Internet social environment [3].

Traditional higher education service faces some problems, such as the training contents are diverse, training and application are separated, and transformation effect of application ability is not good [4]. Micro-lecture supporting pieces, theme and mobile learning, are getting more and more attention [5]. Micro-class model characterized as Internet into the class-room, life practices into the classroom, and creative education into the classroom will become a new trend of curriculum reform [2]. As a new product of the Internet, Micro Learning Resource shows the characteristics of Internet age, featuring visualization, fragmentation, structuralizing and nonlinearity [6]. It is expected that the booming development and wide application of modern mobile information technology will have a great effect on the change of higher education. With the appearance of the first computer changing the development pattern of world industry after 1950s, the internet also changes the mode of social life and economic development. With the popularity of Micro blog, WeChat, micro films, micro-animation, micro websites and other micro-information elements, the mobile Internet market is full of competition. As the main access to the port of the mobile Internet, the intelligent mobile communication tools, such as mobile phone, enable the public to be integrated into the life of the new information consultation, which will provide a good opportunity for developing higher education and improving the ability to acquire information among the wider public. The personal-oriented system learning will become the main learning mode to replace the subject-oriented system learning in the future [7].

\section{MOOC and Micro-Learning}

MOOC. As a new learning method and teaching mode, MOOC is easy to use and with low cost or free. It has been expected that MOOC is causing a revolution of learning and education and is 
changing the existing educational method with long history. Although the current teaching mode of MOOC has been improved compared with the traditional Internet education, there are still some deficiencies. For example, learning is not only about the course itself and the overall teaching atmosphere is also an important factor. It is vital for such aspects as cultivating social relationship, experiencing the group communication, growing up in mind, and how to live, learn and work with other people and these can't be compared with the advantages of traditional teaching mode. The biggest limitation of MOOC mode is linearization curriculum structure. Although there is no strict requirement for time, the learners can arrange for their own learning process with comparative freedom to obtain the good course learning effect. But at present, although there are many selections for learning online and the teachers and the students can communicate flexibly, most MOOC courses are still standardized courses. However, the whole MOOC learning follows the logic of the established curriculum and does not accord with the nature of the students' divergent thinking so the learning ability can't be played efficiently. So the future MOOC should simplify the complicated course requirements, exploring how to construct it at the direction of nonlinear modular combination. It will make the learners manage their learning process dynamically by themselves, play the active nature of divergent thinking, and acquire their own unique learning methods. The students can effectively feedback and regulate the course arrangement and learning by themselves so as to make their learning to the best state.

Micro-Class. The micro-class derived from the concept by David Penrose. Wayne state college launched a program called "the One Minute Professor ", which uses a couple of minutes to explain the most mysterious and amazing thing in the world to the online visitors. In China, there are all kinds of definition about micro class but their meanings are different. Micro-class mainly includes micro-video, micro-teaching case, micro-exercises and other content, the time is often 2-3min, with short, small, refined, defensive features [8]. Micro-class is not a concrete information technology and product, but a change of teaching method. In order to make the learners achieve the best learning effect through autonomous learning, the micro-class is used to attract and stimulate the students' learning passion. The micro-class does not need rules but it can explain the content directly and briefly. The word micro in micro-class means the time is very limited and the knowledge involved is very tiny. But the micro class can make the learners understand the tiny knowledge involved in a short time.

Micro-Lecture. Micro-lecture is with the characteristics of fragmentation, visualization, structuring and nonlinearity. It presents the learning form of fragmentation, the learning content of visualization, the learning style of structuring and the learning approach of nonlinearity. The word micro in micro-lecture is expressed from the four micro angles: time, content, style and the cost and it is reflected that the time of learning is fragmental but linked and the learning content is fragmentation. The appearance of micro-lecture caters to the fragmented and miniaturized mode of education and learning and makes higher education not restricted by time and space to provide a good opportunity for the college education. The classroom mode of "Internet $+"$ helps to integrate the systematic learning and fragmental learning in schools. The individual-oriented systematic learning will replace the subject - oriented systematic learning and become the mainstream learning mode. The classroom mode of "Internet + ", with the characteristics of the Internet into classroom, life practice into classroom, innovative education into classroom, will become a new trend of the reform of school curriculum and teaching and smartphones will have a very broad prospect of application in education and teaching. It will attract increasing attention that micro-lecture supports fragmented, thematic and mobile learning.

\section{Micro-Learning Resource Model}

The existing teaching methods are characteristic of lacking the personal needs for the students, lacking the interaction between the teachers and students and poor quality of teaching resources sharing, so they should draw lessons from the construction concept of MOOC and the features of 
micro class such as being short, interactive, easy to download and expand to reflect its advantages in higher teaching and to learn the relevant skills actively. The platform for micro-information teaching will provide a broader platform for the personalized higher teaching method for cultivating application-oriented talents. According to their own needs and with the help of the platform for micro-information teaching, students can choose and adjust their own learning activities freely, highlighting the students themselves and making the students decide their learning. The students can flexibly learn how to retrieve, acquire and use practical information on the platform for micro-information teaching, which also provide such micro-services as online micro-service and micro-help for the students.

Micro-information Networking. The method combines the micro-information platform with classroom teaching mode, adopting a more flexible and interactive mode of micro-teaching. It highlights the teaching mode of self-control and tutoring online at any time, as well as the personalized, interactive and collaborative mobile Internet micro-teaching of learning. The method tries to construct the platform based on students' autonomous learning and create an open platform for the mobile online learning, changing the past old teaching form "a class, a teacher, a kind of teaching material and a piece of chalk" and fully meet the needs of modern higher teaching and learning.

Micro-education Interacting. The interactive teaching mode is transformed from the short single classroom teaching mode to the teaching platform of micro-information teaching. The platform for micro-information teaching provides more human and personalized service to order micro-teaching for the students to enhance students' self-learning consciousness. According to the actual demands of each students, it can strengthen the interaction with the individuals and achieve the interactive teaching method aiming at improving the practicing ability to gather, screen and apply information.

\section{Summary}

Mobile learning is the major way to learn recently and the way of learning adapts to the needs of fragmentation of knowledge and time in the era of mobile Internet with the target of realizing the learning of any content at any time, at any place and in any way. So, mobile learning requires the learning content must be brief and those audio-visual material easy to attract the learners' attention and the micro-content that can be learnt in the fragmental time are the major form of mobile learning resources. Based on the practical exploration of micro-lecture and mobile Internet and with the support of mobile communication technology and social media, the micro-lecture is deeply analyzed and researched to make micro-lecture better serve students' learning and teachers' teaching, constructing a more appropriate form of digital resources for students' learning and a new effective mode of teaching resources development and realizing the co-construction and co-sharing of good micro-lecture resources. Meanwhile, the micro-class under the mobile network should be based on the teaching video as the main carrier and reflects that teachers develop all kinds of activities of teaching and learning aiming at some teaching points and teaching links in the process of teaching in the classroom. The design of micro-lecture should embody the meaning of micro to satisfy the needs of fragmental and mobile learning and the structure of micro-lecture often includes the opening, learning objectives, the steps of how to solve the problem, testing, conclusion and the ending. These parts of micro-lecture are designed nonlinearly at present. It needs further research whether micro-lecture can be designed nonlinearly to separate the content of different structure existing in the same video and realize the on-demand playback of each part's content.

\section{Acknowledgements}

The work reported in this paper was financially supported by the Scientific Research Fund of Instructional Software of Hechi University (grant no. 2015ER08). The writing committee would like to acknowledge Hechi University for its efforts in supplying laboratory and research instrument. 


\section{References}

[1] W. Jiang, Y.H. Su: Proc. 2017 3rd Annual International Conference on Modern Education and Social Science (Nanjing, China, April 21, 2017). p. 700-703.

[2] Z.L. Wang, X.Y. Li and J. Lin: Journal of Distance Education, (2015) No.4, p.14-21. (In Chinese)

[3] Y. Yu, Y.G. Zhao: Research in Higher Education of Engineering, (2017) No.4, p.187-191. (In Chinese)

[4] J. Yu, Y.Y. Hao, M. Zhao and B. Ming: Library Development, (2015) No.10, p.62-67. (In Chinese)

[5] B. Liang, S.P. Li: Modern Educational Technology, Vol. 24 (2014) No.6, p.27-31. (In Chinese)

[6] J.L. Cen: China Educational Technology, (2016) No.12, p.97-100. (In Chinese)

[7] Z.L. Wang: Journal of Distance Education, Vol. 34 (2016) No.4, p.9-16. (In Chinese)

[8] W. Jiang, Y.H. Su: Proc. 2017 International Conference on Frontiers in Educational Technologies and Management Sciences (Sanya, China, OCT 7, 2017). p. 575-579. 